\title{
Bitter Taste Receptors for Saccharin and Acesulfame K
}

\author{
Christina Kuhn, ${ }^{1}$ Bernd Bufe, ${ }^{1}$ Marcel Winnig, ${ }^{1}$ Thomas Hofmann, ${ }^{2}$ Oliver Frank, ${ }^{2}$ Maik Behrens, ${ }^{1}$ \\ Tatjana Lewtschenko, ${ }^{2}$ Jay P. Slack, ${ }^{3}$ Cynthia D. Ward, ${ }^{3}$ and Wolfgang Meyerhof ${ }^{1}$ \\ ${ }^{1}$ German Institute of Human Nutrition Potsdam-Rehbruecke, Department of Molecular Genetics, 14558 Nuthetal, Germany, ${ }^{2}$ Institute of Food Chemistry, \\ University of Münster, 48149 Münster, Germany, and ${ }^{3}$ Givaudan Flavors Corporation, Cincinnati, Ohio 45216
}

\begin{abstract}
Weight-conscious subjects and diabetics use the sulfonyl amide sweeteners saccharin and acesulfame $\mathrm{K}$ to reduce their calorie and sugar intake. However, the intrinsic bitter aftertaste, which is caused by unknown mechanisms, limits the use of these sweeteners. Here, we show by functional expression experiments in human embryonic kidney cells that saccharin and acesulfame K activate two members of the human TAS2R family (hTAS2R43 and hTAS2R44) at concentrations known to stimulate bitter taste. These receptors are expressed in tongue taste papillae. Moreover, the sweet inhibitor lactisole did not block the responses of cells transfected with TAS2R43 and TAS2R44, whereas it did block the response of cells expressing the sweet taste receptor heteromer hTAS1R2-hTAS1R3. The two receptors were also activated by nanomolar concentrations of aristolochic acid, a purely bitter-tasting compound. Thus, hTAS2R43 and hTAS2R44 function as cognate bitter taste receptors and do not contribute to the sweet taste of saccharin and acesulfame K. Consistent with the in vitro data, cross-adaptation studies in human subjects also support the existence of common receptors for both sulfonyl amide sweeteners.
\end{abstract}

Key words: TAS2R; bitter taste; saccharin; acesulfame K; aristolochic acid; mRNA localization

\section{Introduction}

Mammals discriminate the five taste modalities salty, sour, sweet, bitter, and umami (Lindemann, 2001). Bitter taste causes aversive actions in animals and humans and therefore plays an important role in protecting the organism from ingesting toxic substances, whereas sweet taste is attractive, indicating high-caloric food. The use of artificial sweeteners, which show greatly enhanced sweetness compared with sucrose and have very low caloric value, is steadily increasing (Bar and Biermann, 1992; Hinson and Nicol, 1992; Schiffman and Gatlin, 1993; Leclercq et al., 1999; Ilback et al., 2003). Weight-conscious subjects and diabetics use these sweeteners to reduce their calorie and sugar intake (Hinson and Nicol, 1992; Ilback et al., 2003). However, the two widely used sulfonyl amide sweeteners, saccharin and acesulfame $\mathrm{K}$, possess an intrinsic lingering bitter aftertaste, which increases with higher concentrations and limits their use (Schiffman et al., 1979; Horne et al., 2002). It has been presumed that the bitter aftertaste of these sweeteners in humans or the aversive action in animals is a result of their ability to stimulate special sweet taste receptors (Sclafani and Nissenbaum, 1985) or, alternatively, receptors sensitive to bitter compounds (Bartoshuk et al., 1975). The latter possibility is strongly supported by gene-targeted mice devoid of a sweet receptor subunit, which still avoided some artificial sweeteners, including saccharin (Damak et al., 2003). In

Received April 1, 2004; revised 0ct. 1, 2004; accepted 0ct. 5, 2004.

This work was supported by a grant from the German Science Foundation to (W.M.) We thank Dr. J.-D. Raguse (Virchow Hospital, Berlin, Germany) for providing the lingual tissue and acknowledge the expert technical assistance of Ellen Schöley-Pohl, Caryn Crawford, and Natosha Simpson.

Correspondence should be addressed to Wolfgang Meyerhof, German Institute of Human Nutrition PotsdamRehbruecke, Department of Molecular Genetics, Arthur-Scheunert-Allee 114-116, 14558 Nuthetal, Germany. E-mail:meyerhof@mail.dife.de.

D0I:10.1523/JNEUROSCI.1225-04.2004

Copyright $\odot 2004$ Society for Neuroscience $\quad 0270-6474 / 04 / 2410260-06 \$ 15.00 / 0$ mammals, two members of the TAS1R family of G-proteincoupled receptors (TAS1R2 and TAS1R3) mediate sweet taste (Hoon et al., 1999; Nelson et al., 2001; Li et al., 2002; Damak et al., 2003). They heteromerize to form a general sweet taste receptor for a variety of sweet-tasting compounds, including natural sugars and the artificial sweeteners saccharin and acesulfame $\mathrm{K}$ (Zhao et al., 2003). Because it appears highly unlikely that activation of the hTAS2R2-hTAS2R3 heteromer contributes to the bitter taste of saccharin and acesulfame $\mathrm{K}$, we reasoned that their bitter aftertaste is likely caused by their ability to stimulate bitter taste receptors. The TAS2R family of G-protein-coupled receptors, consisting of $\sim 25$ members, is thought to mediate bitter taste, as suggested by anatomical and genetic evidence (Adler et al., 2000; Chandrashekar et al., 2000; Matsunami et al., 2000; Bufe et al., 2002). However, only a few TAS2Rs have known bitter ligands. In mice, functional expression identified cycloheximide as an agonist for mT2R5 (Chandrashekar et al., 2000), with rat T2R9 being the functional ortholog in this species (Bufe et al., 2002). In similar experiments, mT2R8 was susceptible to propylthiouracil (Chandrashekar et al., 2000). In humans, the respective bitter agonists have been identified by functional expression for only three TAS2Rs. $\beta$-glucopyranosides and strychnine activate hTAS2R16 and hTAS2R10, respectively, whereas hTAS2R14 is more broadly tuned to multiple bitter compounds (Bufe et al., 2002; Behrens et al., 2004). The other hTAS2Rs remain orphan receptors with no known agonists.

The observed positive correlation between the perceived bitterness of saccharin and acesulfame K suggests a common mechanism for bitter taste reception and transduction for the two sweeteners, which differs from mechanisms mediating responses to other bitter compounds (Schiffman et al., 1979; Horne et al., 2002). We therefore aimed to identify the hTAS2R receptors mediating the bitter aftertaste of saccharin and acesulfame $\mathrm{K}$ using 
functional expression of hTAS2Rs in transfected cells and psychophysical studies.

\section{Materials and Methods}

Functional expression. Human TAS2R cDNA constructs were used that encoded a plasma membrane-targeting sequence of the rat somatostatin type 3 receptor at the $\mathrm{N}$ terminus of the recombinant polypeptide and a herpes simplex virus glycoprotein D (HSV) epitope at its C terminus (Bufe et al., 2002). The constructs were transiently transfected into human embryonic kidney (HEK)-293T cells that stably express the chimeric G-protein subunit Go16gust44 (Ueda et al., 2003) using Lipofectamine 2000 (Invitrogen, San Diego, CA). They were then seeded at a density of 70,000 $\pm 10,000$ per well in 96-well microtiter plates (Bufe et al., 2002). Expression rates were determined to be 3\% for hTAS2R 43 and $6 \%$ for hTAS2R44 by indirect immunocytochemistry using monoclonal anti-HSV antibody (Novagen, Madison, WI) and secondary anti-mouse IgG antibody coupled to Alexa488 (Molecular Probes, Eugene, OR) (Bufe et al., 2004). Calcium imaging experiments using an automated fluorometric imaging plate reader (FLIPR) (Molecular Devices, Munich, Germany) have been performed 24-32 hr later essentially as described previously (Bufe et al., 2002). Tastants (Sigma-Aldrich, Taufkirchen, Germany) were dissolved and administered in the following (in mM): 130 $\mathrm{NaCl}, 5 \mathrm{KCl}, 10 \mathrm{HEPES}, 2 \mathrm{CaCl}_{2}$, and 10 glucose, $\mathrm{pH}$ 7.4. Transfected cells were challenged with vehicle, saccharin, acesulfame $\mathrm{K}$, aristolochic acid, or other tastants. Based on above estimations, $\sim 2000-4000$ cells contributed to a calcium response recorded from a single well. Data were collected from a minimum of three independent experiments performed at least in triplicate and processed with SigmaPlot (SPSS, Chicago, IL). For dose-response curve calculation, the peak fluorescence responses after compound addition were corrected for and normalized to background fluorescence $\left(\Delta F / F=\left(F-F_{0}\right) / F_{0}\right)$, and baseline noise was subtracted.

Human psychophysical studies. Taste experiments were approved by the local ethical committees. To investigate adaptation, we first determined concentrations of the test solutions that elicited comparable bitter intensities in the subjects. Then, in a first experiment, eight individuals took up aqueous solutions ( $5 \mathrm{ml})$ of $\mathrm{Na}$-saccharin $(20 \mathrm{~mm})$, acesulfame $\mathrm{K}$ $(20 \mathrm{~mm})$, aristolochic acid $(0.02 \mathrm{~mm})$, or salicin $(10 \mathrm{~mm})$ in their oral cavities for $15 \mathrm{sec}$ while gargling and rated the bitter intensities on an intensity scale from 0 to 5 . In a second experiment, after $30 \mathrm{~min}$, the subjects took up $5 \mathrm{ml}$ of $\mathrm{Na}$-saccharin (20 mM), acesulfame K (20 mM), aristolochic acid $(0.02 \mathrm{~mm})$, or salicin $(10 \mathrm{~mm})$ solutions orally and judged bitterness intensities after 15, 30, 45, 60, 75, 90, and $105 \mathrm{sec}$. To investigate cross-adaptation, the subjects spat off these solutions and then sequentially took up $5 \mathrm{ml}$ of acesulfame K $(20 \mathrm{~mm})$, Na-saccharin $(20 \mathrm{~mm})$, aristolochic acid $(0.02 \mathrm{~mm})$, and salicin $(10 \mathrm{~mm})$ and evaluated the bitterness intensities after $15 \mathrm{sec}$ as described previously. After an additional $30 \mathrm{~min}$, the first experiment was repeated. We averaged the data of three different sessions for each subject. Intensity values between individuals, and separate sessions did not differ by $>0.5$ units.

In situ hybridization of human circumvallate papilla. In situ hybridization was mainly performed as described previously (Behrens et al., 2000). Briefly, $20 \mu \mathrm{m}$ cross sections of circumvallate papillae of human tongues were processed and thaw mounted onto positively charged glass slides. Before hybridization, the sections were fixated using $4 \%$ paraformaldehyde in PBS, permeabilized with $0.2 \mathrm{~m}$ hydrochloric acid for $10 \mathrm{~min}$ and $1 \%$ Triton X-100 in PBS for $2 \mathrm{~min}$, and acetylated by treatment with 0.1 $\mathrm{M}$ triethanolamine- $0.25 \%$ acetic anhydride, $\mathrm{pH}$ 8.0. Prehybridization was done at $50^{\circ} \mathrm{C}$ for $5 \mathrm{hr}$, followed by hybridization overnight at $50^{\circ} \mathrm{C}$. The corresponding riboprobes were generated as follows: From expression vectors containing the entire open reading frames of hTAS2R43 and hTAS2R44, respectively, the nucleotide sequences of the coding regions were amplified by PCR using Pfu polymerase and oligonucleotides that add T3 and T7 phage RNA polymerase promoter sequences to the resulting PCR fragments. The PCR fragments were used as templates for in vitro transcription reactions, resulting in the generation of digoxigeninlabeled sense and antisense riboprobes. Probes were used for hybridization at a final concentration of $\sim 500 \mathrm{ng} / \mathrm{ml}$. After hybridization, the slides were washed several times at low stringency, followed by RNase A

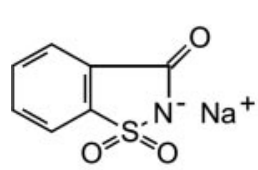

Na-saccharin<smiles></smiles>

acesulfame K<smiles>COc1cccc2c1cc([N+](=O)[O-])c1c(C(=O)[O-])cc3c(c12)OCO3</smiles>

aristolochic acid sodium salt
Figure 1. Structures of the compounds used. Aristolochic acid preparations consist of two compounds, one of which is devoid of the methoxy group.

\section{aristolochic acid}

a

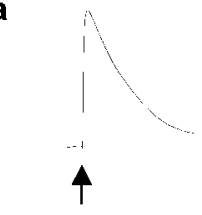

b
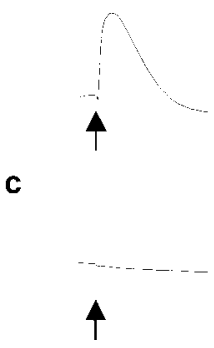

saccharin
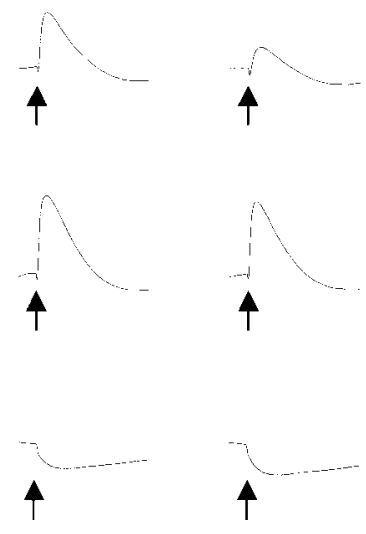

acesulfame $\mathrm{K}$

vehicle
Figure 2. Functional expression of hTAS2R43 and hTAS2R44. Responses of cells expressing hTAS2R43 ( $a$ ) or hTAS2R44 ( $b$ ) or of mock-transfected cells (c) to bath application of $10 \mu \mathrm{m}$ aristolochic acid, $10 \mathrm{~mm}$ saccharin, or $10 \mathrm{~mm}$ acesulfame $\mathrm{K}$ were recorded in the FLIPR. Cells were seeded in 96-well microtiter plates and loaded with Flu04-AM (Molecular Probes). Calcium traces were recorded at an excitation wavelength of $488 \mathrm{~nm}$ and an emission wavelength of 515 $\mathrm{nm}$. Arrows indicate agonist application. Data of a typical experiment were corrected for and normalized to background fluorescence. Calibration: horizontal bar, $100 \mathrm{sec}$; vertical bar, $\Delta F / F=0.1$.

treatment and high-stringency washes using $0.4 \times$ SSC buffer at $50^{\circ} \mathrm{C}$. Hybridized riboprobes were detected using an anti-digoxigenin antibody and colorimetry. Photomicrographs were taken with a CCD camera (RT slider; Diagnostic Instruments, Sterling Heights, MI) mounted to a Zeiss (Oberkochen, Germany) Axioplan microscope.

\section{Results}

We used HEK-293T cells stably expressing the chimeric G-protein $\alpha$-subunit, G16gust44 to couple activation of transfected TAS2R receptors to the release of $\mathrm{Ca}^{2+}$ from intracellular stores, which can be measured using calcium-sensitive fluorescence dyes (Chandrashekar et al., 2000; Bufe et al., 2002; Ueda et al., 2003). As reported previously, the hTAS2Rs were expressed as chimeric polypeptides containing the rat somatostatin receptor type 3 plasma membrane-targeting sequence at their $\mathrm{N}$ termini and a herpes simplex virus glycoprotein D epitope at their $\mathrm{C}$ termini (Bufe et al., 2002). Application of saccharin (Fig. 1) to cells expressing hTAS2R43 or hTAS2R44 elicited robust transient elevation of cytosolic $\mathrm{Ca}^{2+}$ concentrations $\left[\mathrm{Ca}^{2+}\right]_{\mathrm{i}}$ (Fig. $\left.2 a, b\right)$, with threshold values of activation of $0.17 \pm 0.11$ and $0.08 \pm 0.06$ $\mathrm{mM}$ and $\mathrm{EC}_{50}$ values of $1.7 \pm 0.02$ and $1.1 \pm 0.01 \mathrm{~mm}$, respectively 
(Fig. 3a,b). Mock-transfected cells or cells transfected with 23 other hTAS2Rs (Bufe et al., 2002; Shi et al., 2003) did not respond to saccharin up to $20 \mathrm{~mm}$ (Fig. $2 c$; results not shown). Acesulfame K (Fig. 1), the other widely used sulfonyl amide sweetener, also elicited robust responses in hTAS2R44-expressing cells (Fig. 2b), with a threshold value of activation of $0.25 \pm$ $0.09 \mathrm{~mm}$ and an $\mathrm{EC}_{50}$ value of $2.5 \pm 0.01$ mu (Fig. 3b). However, hTAS2R43-expressing cells only weakly responded to acesulfame K (Fig. 2a), with a threshold value of $3.1 \pm 1.6 \mathrm{~mm}$ and an estimated $\mathrm{EC}_{50}$ value $>10 \mathrm{~mm}$ (Fig. $3 a$ ). These data suggest that hTAS2R43 and hTAS2R44 function as taste receptors for saccharin and acesulfame $\mathrm{K}$ and are in agreement with previous psychophysical studies that suggested the existence of a common receptor mechanism for the bitter taste of these two sweeteners (Schiffman et al., 1979; Horne et al., 2002).

At this point, a question that remained was whether hTAS2R43 and hTAS2R44 mediate the bitter taste of the sulfonyl sweeteners or contribute to their sweet taste. If they are indeed true bitter receptors, then at least one purely bitter-tasting compound must activate them. We therefore challenged cells expressing hTAS2R43 or hTAS2R44 with various bitter compounds, including denatonium benzoate $(10 \mu \mathrm{M})$, aristolochic acid $(10 \mu \mathrm{M})$, sucrose octaacetate $(1 \mathrm{mM})$, nicotine $(330 \mu \mathrm{M})$, caffeine $(1 \mathrm{mM})$, theophylline $(10 \mathrm{~mm})$, epicatechine $(5 \mathrm{~mm})$, propylthiouracil $(250 \mu \mathrm{M})$, phenylthiocarbamide $(500 \mu \mathrm{M})$, strychnine $(100 \mu \mathrm{M})$, humolone $(92 \mu \mathrm{M})$, and salicin $(10 \mathrm{~mm})$. Of these, only application of aristolochic acid (Fig. 1) [the primary bitter principle of Aristolochia species present in many oriental herbal remedies (Ganshirt, 1953)] to cells expressing hTAS2R43 and hTAS2R44 elicited transient elevation of $\left[\mathrm{Ca}^{2+}\right]_{\mathrm{i}}$ (Fig. $\left.2 a, b\right)$, with threshold values of activation of $1.3 \pm 1.1$ and $16 \pm 9.5 \mathrm{nM}$ and $\mathrm{EC}_{50}$ values of $81 \pm 0.8$ and $455 \pm 5.3 \mathrm{nM}$, respectively (Fig. $3 a, b$ ). Thus, aristolochic acid is able to activate the two hTAS2Rs at concentrations 2000- to 20,000-fold lower than those observed for the two sulfonyl amide sweeteners, unambiguously confirming their role as bitter taste receptors. This conclusion is also supported from experiments using the sweet taste inhibitor lactisole. This substance reduces the sweet taste of many compounds (Schiffman et al., 1999) but does not affect bitterness (Johnson et al., 1994). Lactisole also inhibited the calcium responses induced by sweeteners in cells transfected with cDNAs encoding the subunits hTAS1R2 and hTAS1R3 of the general mammalian sweet taste receptor heteromer (Nelson et al., 2001; Li et al., 2002). Lactisole can therefore discriminate sweet taste from bitter taste receptors by blocking the former but not the latter. Consistent with these data, Figure 4 demonstrates that, whereas lactisole completely blocked the calcium response to saccharin in cells expressing the sweet taste receptor heteromer hTAS1R2 and hTAS1R3 (Fig. 4c), it had no effect on cells expressing hTAS2R43 and hTAS2R44 (Fig. $4 a, b)$. Moreover, we administered compounds that elicit sweet, bitter, or umami taste to cells expressing hTAS2R43 and hTAS2R44, and none of them were able to induce any response (Fig. 5). These results indicate that hTAS2R43 and hTAS2R44 are true bitter receptors for aristolochic acid, saccharin, and acesulfame K.

To further examine the contribution of the two receptors to human bitter taste perception, we performed adaptation and b

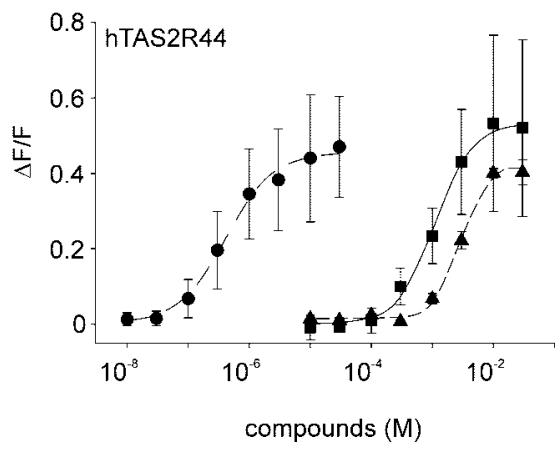

compounds $(\mathrm{M})$

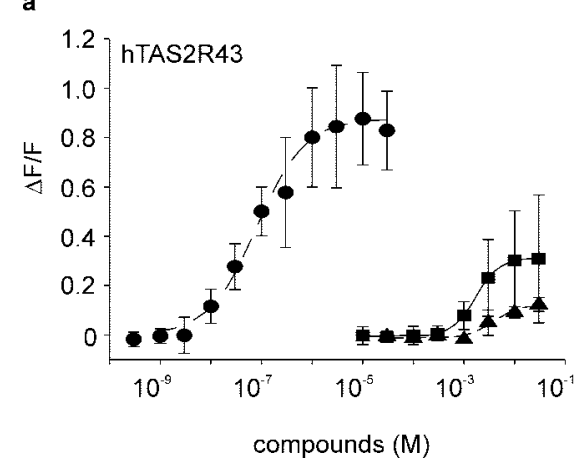

Figure 3. Properties of hTAS2R43 and hTAS2R44 in transfected cells. Dose-response relationships of the effects of aristolochic acid (circles), saccharin (squares), and acesulfame K (triangles) on $\left[\mathrm{Ca}^{2+}\right]_{\mathrm{i}}$ in cells expressing hTAS2R43 ( $a$ ) or hTAS2R44 ( $b$ ). Cells ubtracted.

$\mathbf{a}$

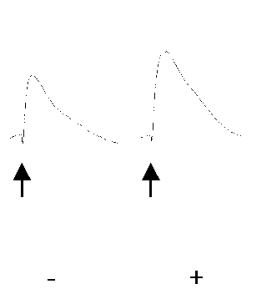

b

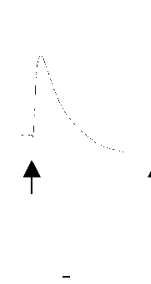

c

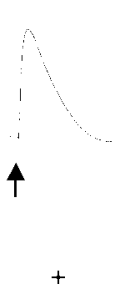

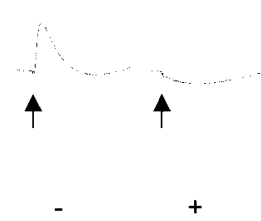

Figure 4. Effects of lactisole on cells expressing bitter or sweet taste receptors. Calcium traces of cells transfected with cDNAs for hTAS2R43 $(a)$, hTAS2R44 $(b)$, or the sweet taste receptor subunits hTAS1R2 and hTAS1R3 ( $c$ ) were recorded as described in Figure 2. Cells were stimulated with $10 \mathrm{~mm}$ saccharin in the absence $(-)$ or presence $(+)$ of $0.5 \mathrm{~mm}$ lactisole. Arrows indicate bath application of saccharin or of the mixture of saccharin and lactisole. Data of a typical experiment were corrected for and normalized to background fluorescence. Calibration: horizontal bar, $100 \mathrm{sec}$; vertical bar, $\Delta F / F=0.1$.

cross-adaptation experiments. It is well known that taste responses decline with prolonged stimulation by bitter compounds (Bartoshuk et al., 1964; Pfaffmann, 1965; Vonb’Ek'Esy, 1965). This phenomenon, referred to as adaptation, has successfully been used to elucidate whether taste stimuli use separate or shared signal transduction mechanisms and bitter taste receptors (Froloff et al., 1998; Bufe et al., 2002; Keast and Breslin, 2002). Figure $6 a$ shows that subjects perceived, at the concentrations used, aristolochic acid and the two sulfonyl amide sweeteners with the same bitter intensity as the control compound salicin, a bitter agonist for hTAS2R16 that does not activate hTAS2R43 and hTAS2R44 (Fig. 5) (Bufe et al., 2002). The salicin response adapted during exposure time but did not cross-adapt with those for the three compounds under study. Furthermore, it was fully reversible, making salicin a suitable control compound. Figure $6 b$ shows that the response to aristolochic acid declined to $\sim 15 \%$ of the original value during $90 \mathrm{sec}$. Longer exposure times did not cause stronger desensitization (data not shown). Under these conditions, the subjects showed only marginal residual responses to acesulfame $\mathrm{K}$ and saccharin, suggesting that exposure to aristolochic acid more or less completely desensitized the subjects' responses to the sulfonyl amides. This finding supports the existence of common receptors for both sulfonyl amide sweeteners and aristolochic acid and suggests the absence of additional separate hTAS2R bitter taste receptors for the sulfonyl amide sweeteners. Also, the perceived bitter intensities of saccharin and ace- 
a

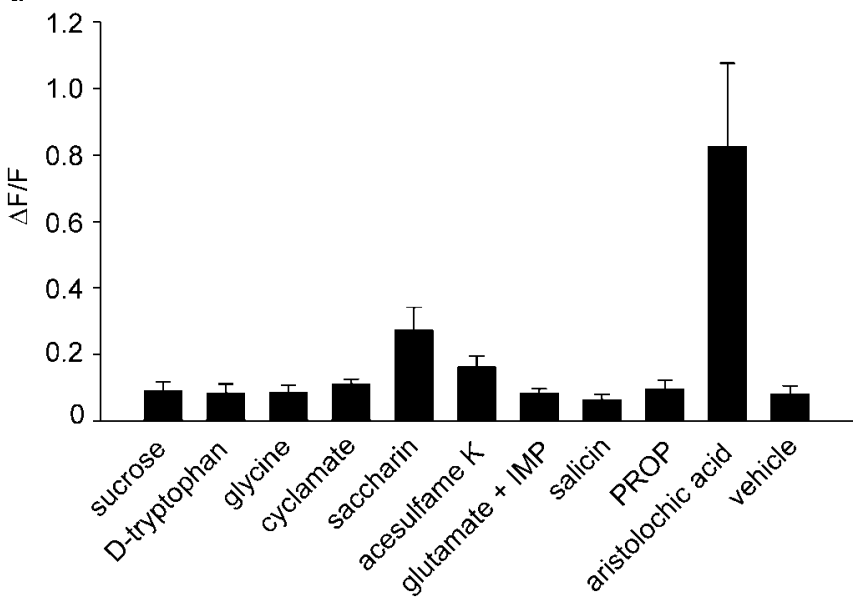

b

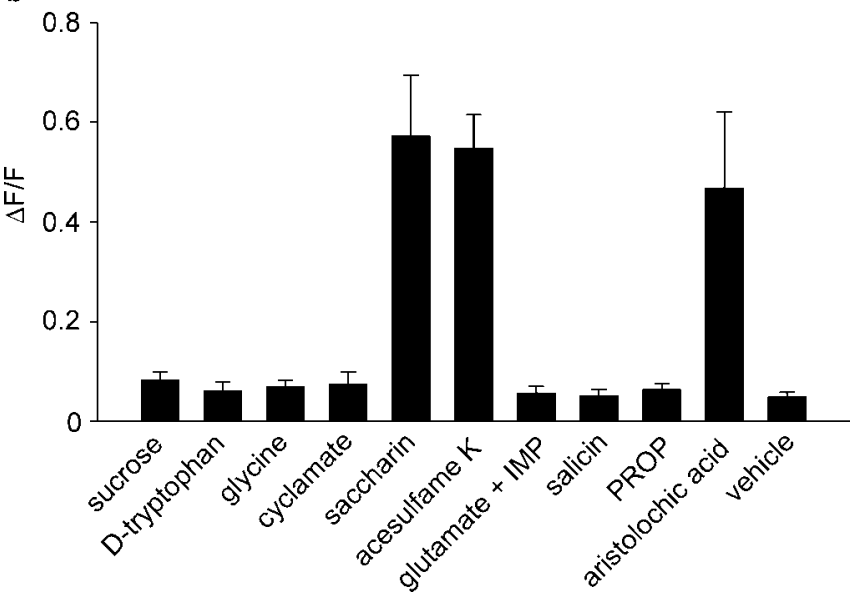

Figure 5. Responses of hTAS2R43- and hTAS2R44-expressing cells to various taste compounds. Calcium responses of cells expressing hTAS2R43 ( $a$ ) and hTAS2R44 ( $b$ ) that have been challenged with vehicle (control), sucrose $(75 \mathrm{~mm})$, o-tryptophan $(10 \mathrm{~mm})$, glycine $(75 \mathrm{~mm})$, Na-cyclamate $(10 \mathrm{~mm})$, Na-saccharin $(10 \mathrm{~mm})$, acesulfame $\mathrm{K}(10 \mathrm{~mm})$, a mixture of Na-glutamate $(10 \mathrm{~mm})$ and inosine monophosphate $(1 \mathrm{~mm})$ (glutamate + IMP), salicin (10 mM), propylthiouracil (PROP) $(0.25 \mathrm{~mm})$, or aristolochic acid Na-salt $(0.01 \mathrm{~mm})$. Data of three independent experiments performed in quadruplicate were processed in SigmaPlot. Data were corrected for and normalized to background fluorescence.

sulfame K gradually decreased in the subjects within 105 and 90 sec to $<10$ and $7 \%$, respectively (Fig. $6 c, d$ ), with no additional desensitization after longer treatment (results not shown). We also investigated whether cross-adaptation using the sulfonyl amides as the primary taste stimulus could reduce the perceived bitterness of the respective two other bitter agonists applied subsequently. Indeed, the test subjects perceived that aristolochic acid and acesulfame $\mathrm{K}$ were much less bitter after the saccharin stimulus than in the absence of it (Fig. $6 c$ ). When the crossadaptation experiment was reversed and acesulfame $\mathrm{K}$ was used as the first stimulus, the bitter ratings of saccharin and aristolochic acid were similarly reduced (Fig. $6 d$ ). These results suggest that prestimulation with one sulfonyl amide strongly desensitized the subsequent responses to the other one and aristolochic acid. Again, this result is in favor of common receptors for aristolochic acid and the two sulfonyl amide sweeteners. However, the observed cross-desensitizations were smaller than that induced by aristolochic acid. Saccharin and acesulfame K are weak agonists and activate hTAS3R43 only partially. It is therefore not surprising that they also cannot completely desensitize the re- a
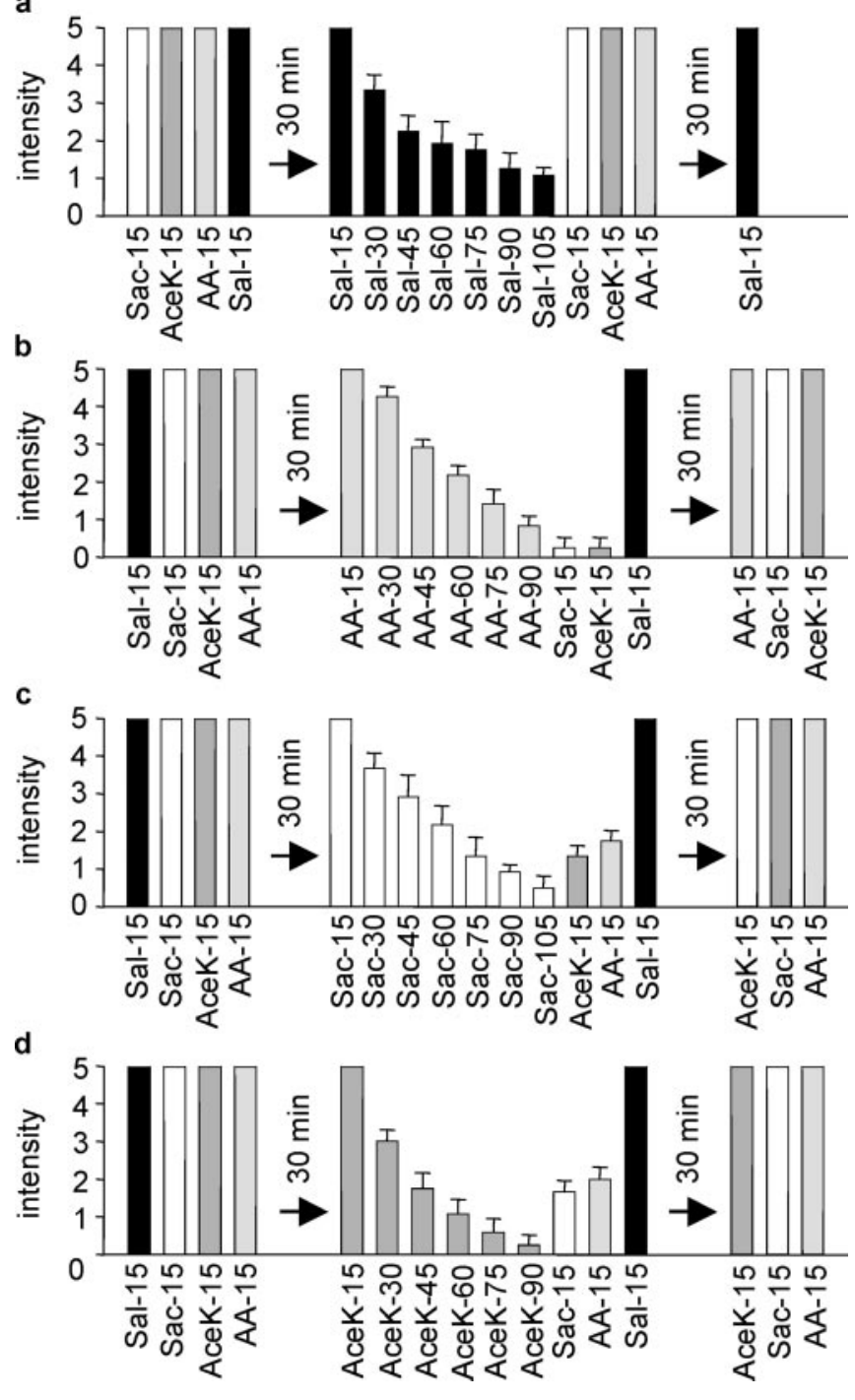

Figure 6. Adaptation and cross-adaptation of psychophysical responses elicited by the sulfonyl amides and aristolochic acid. In the beginning of the experiment, the subjects rated the bitterness of all four solutions after $15 \mathrm{sec}$. Then, they took up the primary bitter solution for prolonged times and rated its bitterness at the indicated times. After the panelists spat off the primary bitter solution, they sequentially tasted the other three test solutions and rated their bitter intensity after $15 \mathrm{sec}$. To assess reversibility, the subjects sequentially rated 30 min later the bitterness of all four test solutions after $15 \mathrm{sec}$. $a$, Adaptation to the bitterness of salicin used as a control compound and lack of cross-adaptation with responses to saccharin, acesulfame $K$, and aristolochic acid. $b$, Adaptation to the bitter response of aristolochic acid and crossadaptation with those of both sulfonyl amide sweeteners. Note that the response to salicin was not affected. c, Adaptation to the bitter taste of saccharin and cross-adaptation with those of acesulfame $K$ and aristolochic acid. $d$, Adaptation to the bitter taste of acesulfame $K$ and crossadaptation with those of saccharin and aristolochic acid. AA, aristolochic acid; AceK, acesulfame K; Sac, saccharin; Sal, salicin.

sponses to the sulfonyl amide sweeteners, arguing against the existence of additional receptors for the sulfonyl amide sweeteners. However, additional hTAS2Rs that cannot be activated by the sulfonyl amides could exist for aristolochic acid.

If hTAS2R43 and hTAS2R44 are genuine taste receptors, their mRNAs should be present in the taste tissue. Therefore, we analyzed the expression of the genes encoding hTAS2R43 and hTAS2R44 in circumvallate papillae by in situ hybridization experiments with cRNA probes for both hTAS2R43 and hTAS2R44 (Fig. 7). Both probes identified a few positive cells in circumvallate taste buds. Although the signals for hTAS2R43 are weaker 


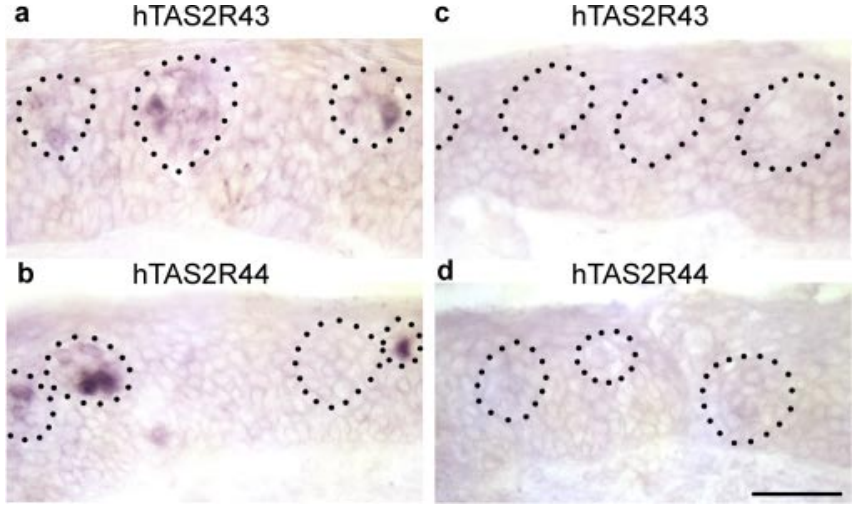

Figure 7. In situ hybridization of hTAS2R43 and hTAS2R44 mRNAs in human circumvallate papillae. Twenty micrometer cryostat cross sections of human circumvallate papillae were hybridized with digoxigenin-labeled antisense $(a, b)$ or sense $(c, d)$ riboprobes. After hybridization, sections were treated with RNase A and subjected to high-stringency washes. Probes were detected by using an anti-digoxigenin antibody and colorimetry. Taste buds are circled. Note that both receptor mRNAs were detected in a subset of cells of the majority of taste buds. Scale bar, $50 \mu \mathrm{m}$.

than those of hTAS2R44, the number of cells expressing these two receptors is similar and comparable with those obtained for hTAS2R16 and hTAS2R14 (Bufe et al., 2002; Behrens et al., 2004). These data independently support the role of hTAS2R43 and hTAS2R44 as lingual bitter taste receptors.

\section{Discussion}

Using a combination of human psychophysics and functional expression of bitter taste receptors in transfected cell lines, we have examined the basis for the bitter aftertaste of the sulfonyl amide sweeteners saccharin and acesulfame K. Our data clearly show that hTAS2R43 and hTAS2R44 are expressed in taste papillae of the tongue. hTAS2R43 and hTAS2R44 were activated in transfected cells by saccharin and acesulfame $\mathrm{K}$ at concentrations known to elicit bitter taste (Bartoshuk, 1979; Schiffman and Gatlin, 1993; Schiffman et al., 1995; Horne et al., 2002). Three additional findings in the course of our study also strongly suggest that hTAS2R43 and hTAS2R44 do not contribute to the sweet taste of the sulfonyl amides but mediate the bitter aftertaste. First, the purely sweet-tasting compounds sucrose and D-tryptophan were unable to activate the recombinant receptors. Second, hTAS2R43 and hTAS2R44 show a two to three order-ofmagnitude higher sensitivity to the purely bitter-tasting compound aristolochic acid. Third, the sweet inhibitor lactisole did not affect the responses elicited by the sulfonyl amide sweeteners in cells transfected with hTAS2R43 and hTAS2R44. The conclusion is also supported by mice models devoid of the sweet taste receptor subunit TAS1R3, which still show aversive responses to artificial sweeteners (Damak et al., 2003). These data also predict that the bitter taste associated with other artificial sweeteners is likely to be caused by activation of other TAS2R bitter taste receptors.

hTAS2R43 and hTAS2R44 show a pronounced sequence relationship. The two hTAS2R paralogs represent the two closest related members of the entire hTAS2R family (Bufe et al., 2002). They show $89 \%$ amino acid identity (data not shown), which explains their functional similarities. Nonetheless, saccharin, acesulfame K, and aristolochic acid activate the two receptors differently. The $\mathrm{EC}_{50}$ values obtained for aristolochic acid differ approximately fivefold between the two receptors, and we also observed that this compound has a lower efficacy at hTAS2R44.
In marked contrast, saccharin displays similar $\mathrm{EC}_{50}$ values at both receptors but has lower efficacy at hTAS2R43, whereas acesulfame $\mathrm{K}$ only weakly activates this receptor. The data therefore suggest that hTAS2R43 and hTAS2R44 contribute differently to the perceived bitterness of the sulfonyl sweeteners and aristolochic acid.

Another question that arises is how many hTAS2Rs contribute to the bitter taste of the sulfonyl amide sweeteners. Although the functional expression studies did not identify additional receptors, we may have overlooked them because of insufficient coupling to the chimeric G-protein or lack of cell surface expression (Bufe et al., 2002, 2004). The observation that the bitter perception of the sulfonyl amide sweeteners completely desensitizes after previous stimulation by aristolochic acid suggests that there are probably no additional separate hTAS2R receptors for saccharin and acesulfame $\mathrm{K}$. It is important to stress here that the recently identified receptor for the related compound 6-nitrosaccharin, which has been designated as hT2R61, is identical to hTAS2R43 and not a separate sulfonyl amide receptor (Pronin et al., 2004). Vice versa, based on the incomplete cross-adaptation using the sulfonyl amides as the primary stimuli, we cannot preclude the existence of other receptors for aristolochic acid.

Last but not least, the present work has deorphanized two TAS2R receptors. This receptor family, which consists of $\sim 25$ members in humans and $\sim 35$ members in mice (Bufe et al., 2002; Shi et al., 2003), has been equated to bitter taste receptors based on anatomical, functional, and genetic evidence for a few selected TAS2R family members only (Adler et al., 2000; Chandrashekar et al., 2000; Matsunami et al., 2000; Bufe et al., 2002). In view of the large still uncharacterized repertoire of TAS2Rs, the identification of the bitter receptors for aristolochic acid and sulfonyl amide sweeteners is an important step toward understanding the biological function of this complex gene family.

\section{References}

Adler E, Hoon MA, Mueller KL, Chandrashekar J, Ryba NJ, Zuker CS (2000) A novel family of mammalian taste receptors. Cell 100:693-702.

Bar A, Biermann C (1992) Intake of intense sweeteners in Germany. Z Ernahrungswiss 31:25-39.

Bartoshuk LM (1979) Bitter taste of saccharin related to the genetic ability to taste the bitter substance 6-n-propylthiouracil. Science 205:934-935.

Bartoshuk LM, McBurney DH, Pfaffmann C (1964) Taste of sodium chloride solutions after adaptation to sodium chloride: implications for the "water taste". Science 143:967-968.

Bartoshuk LM, Jacobs HL, Nichols TL, Hoff LA, Ryckman JJ (1975) Taste rejection of nonnutritive sweeteners in cats. J Comp Physiol Psychol 89:971-975.

Behrens M, Venkatraman G, Gronostajski RM, Reed RR, Margolis FL (2000) NFI in the development of the olfactory neuroepithelium and the regulation of olfactory marker protein gene expression. Eur J Neurosci 12:1372-1384.

Behrens M, Brockhoff A, Kuhn C, Bufe B, Winnig M, Meyerhof W (2004) The human taste receptor hTAS2R14 responds to a variety of different bitter compounds. Biochem Biophys Res Commun 319:479-485.

Bufe B, Hofmann T, Krautwurst D, Raguse JD, Meyerhof W (2002) The human TAS2R16 receptor mediates bitter taste in response to betaglucopyranosides. Nat Genet 32:397-401.

Bufe B, Schöley-Pohl E, Krautwurst D, Hofmann T, Meyerhof W (2004) Identification of human bitter taste receptors. Am Chem Soc Symp S 867:45-59.

Chandrashekar J, Mueller KL, Hoon MA, Adler E, Feng L, Guo W, Zuker CS, Ryba NJ (2000) T2Rs function as bitter taste receptors. Cell 100:703-711.

Damak S, Rong M, Yasumatsu K, Kokrashvili Z, Varadarajan V, Zou S, Jiang P, Ninomiya Y, Margolskee RF (2003) Detection of sweet and umami taste in the absence of taste receptor T1r3. Science 301:850-853.

Froloff N, Lloret E, Martinez JM, Faurion A (1998) Cross-adaptation and 
molecular modeling study of receptor mechanisms common to four taste stimuli in humans. Chem Senses 23:197-206.

Ganshirt H (1953) Isolation of aristolochic acid from various Aristolochiaceae and its quantitative determination (in German). Pharmazie 8:584592.

Hinson AL, Nicol WM (1992) Monitoring sweetener consumption in Great Britain. Food Addit Contam 9:669-680.

Hoon MA, Adler E, Lindemeier J, Battey JF, Ryba NJP, Zuker CS (1999) Putative mammalian taste receptors: a class of taste-specific GPCRs with distinct topographic selectivity. Cell 96:541-551.

Horne J, Lawless HT, Speirs W, Sposato D (2002) Bitter taste of saccharin and acesulfame-K. Chem Senses 27:31-38.

Ilback NG, Alzin M, Jahrl S, Enghardt-Barbieri H, Busk L (2003) Estimated intake of the artificial sweeteners acesulfame- $\mathrm{K}$, aspartame, cyclamate and saccharin in a group of Swedish diabetics. Food Addit Contam 20:99-114.

Johnson C, Birch GG, MacDougall DB (1994) The effect of the sweetness inhibitor 2(-4-methoxyphenoxy)propanoic acid (sodium salt) (NaPMP) on the taste of bitter-sweet stimuli. Chem Senses 19:349-358.

Keast RS, Breslin PA (2002) Cross-adaptation and bitterness inhibition of L-tryptophan, L-phenylalanine and urea: further support for shared peripheral physiology. Chem Senses 27:123-131.

Leclercq C, Berardi D, Sorbillo MR, Lambe J (1999) Intake of saccharin, aspartame, acesulfame $\mathrm{K}$ and cyclamate in Italian teenagers: present levels and projections. Food Addit Contam 16:99-109.

Li X, Staszewski L, Xu H, Durick K, Zoller M, Adler E (2002) Human receptors for sweet and umami taste. Proc Natl Acad Sci USA 99:4692-4696.

Lindemann B (2001) Receptors and transduction in taste. Nature 413:219-225.

Matsunami H, Montmayeur JP, Buck LB (2000) A family of candidate taste receptors in human and mouse. Nature 404:601-604.
Nelson G, Hoon MA, Chandrashekar J, Zhang Y, Ryba NJ, Zuker CS (2001) Mammalian sweet taste receptors. Cell 106:381-390.

Pfaffmann C (1965) Gustatory adaptation (in French). Actual Neurophysiol 6:85-97.

Pronin AN, Tang H, Connor J, Keung W (2004) Identification of ligands for two human bitter T2R receptors. Chem Senses 29:583-593.

Schiffman SS, Gatlin CA (1993) Sweeteners: state of knowledge review. Neurosci Biobehav Rev 17:313-345.

Schiffman SS, Reilly DA, Clark III TB (1979) Qualitative differences among sweeteners. Physiol Behav 23:1-9.

Schiffman SS, Booth BJ, Losee ML, Pecore SD, Warwick ZS (1995) Bitterness of sweeteners as a function of concentration. Brain Res Bull 36:505-513.

Schiffman SS, Booth BJ, Sattely-Miller EA, Graham BG, Gibes KM (1999) Selective inhibition of sweetness by the sodium salt of $+/-2-(4-$ methoxyphenoxy)propanoic acid. Chem Senses 24:439-447.

Sclafani A, Nissenbaum JW (1985) On the role of the mouth and gut in the control of saccharin and sugar intake: a reexamination of the shamfeeding preparation. Brain Res Bull 14:569-576.

Shi P, Zhang J, Yang H, Zhang YP (2003) Adaptive diversification of bitter taste receptor genes in mammalian evolution. Mol Biol Evol 20:805-814.

Ueda T, Ugawa S, Yamamura H, Imaizumi Y, Shimada S (2003) Functional interaction between T2R taste receptors and G-protein $\alpha$ subunits expressed in taste receptor cells. J Neurosci 23:7376-7380.

Vonb'Ek'Esy G (1965) The effect of adaptation of the taste threshold observed with a semiautomatic gustometer. J Gen Physiol 48:481-488.

Zhao GQ, Zhang Y, Hoon MA, Chandrashekar J, Erlenbach I, Ryba NJ, Zuker CS (2003) The receptors for mammalian sweet and umami taste. Cell 115:255-266. 